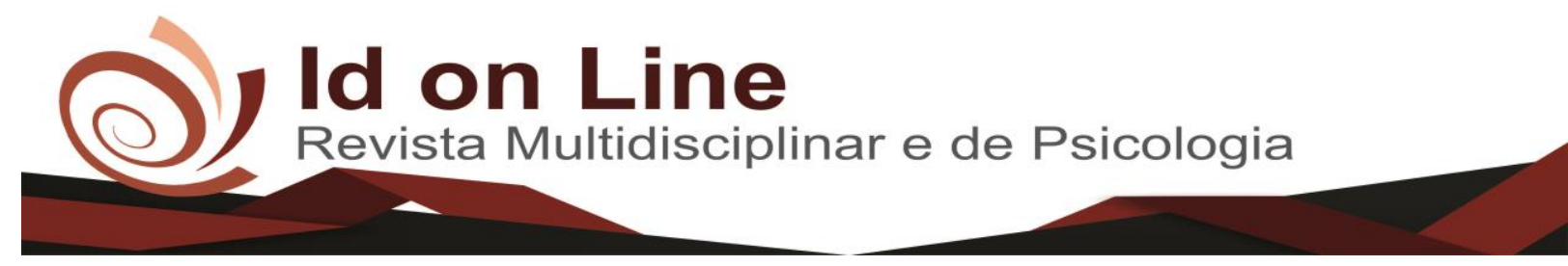

Comment

\title{
A Importância da Participação da Família na Educação Escolar
}

\author{
Sheylla Michelle Barros Ferreira ${ }^{1}$; Marta Callou Barros Coutinho ${ }^{2}$; Maria do Socorro Cecílio Sobral ${ }^{3}$
}

\begin{abstract}
Resumo: O presente texto visa iniciar uma relação à cerca das interações família/escola, buscando desconstruir preconceitos que cercam os modelos de famílias na atualidade. Aponta que os papéis da família e da escola se modificaram ao longo das últimas décadas a ponto de, na atualidade, serem coautoras das decisões administrativas, pedagógicas e sociais nas unidades escolares. A relação família/escola, nos dias atuais, tem que ser levado em conta um conjunto de determinantes da nossa realidade que cada vez mais, exige o desenvolvimento da aprendizagem, competências e habilidades dos alunos, para que se relacionem com os demais integrantes da comunidade escolar e da sociedade em que estão inseridos sendo essa a justificativa para esse estudo que traz como questão verificar como está essa relação e como objetivo analisar interações família/escola. O texto traz como resultado uma reflexão sobre a prática pedagógica, com maior intercâmbio com a família, as relações entre o envolvimento da família com a vida escolar e a aprendizagem. A família reflete os problemas da sociedade, bem como a presença ou ausência de valores nos diversos contextos, é importante que a escola mantenha relação de parceria com a família. A metodologia para desenvolver este trabalho aconteceu através da pesquisa bibliográfica, permitindo reflexões críticas e possibilitando alteração da realidade social, numa abordagem qualitativa com base na corrente teórica do materialismo dialético. Esses foram os pressupostos que nortearam o rumo da investigação sobre o papel da família no desempenho escolar das crianças. Ao realizar o projeto fez-se necessária uma análise da realidade institucional da educação, do perfil de seus alunos.
\end{abstract}

Palavras-Chave: Participação. Família. Educação.

\section{The Importance of the Family Participation in School Education}

\begin{abstract}
The present study aims to initiate an interaction between family and school, seeking to deconstruct the bias that surround the models of families in the present times. It points out that the roles of the family and school have changed over the last decades to the point where they currently co-author administrative, pedagogical and social decisions in school units. The family and school relationship, today, has to be taken into account a set of determinants of our reality that increasingly requires the development of learning, skills and abilities of students, to relate to the other members of the community school and the society in which they are inserted. This is the justification for this study that brings as a question to verify how this relationship is and to analyze family-school interactions. The study brings as a result a reflection on the pedagogical practice, with greater interchange with the family, the relations between the involvement of the family with the school life and the learning process. The family reflects the problems of society, as well as the presence or absence of values in different contexts, it is important that the school maintains a partnership relationship with the family. The methodology that was used to develop this work was bibliographical research, allowing critical reflections and making possible the alteration of social reality, in a qualitative approach based on the theoretical current of dialectical materialism. These were the assumptions that guided the investigation of the role of the family in the children's school performance. During the project, it was necessary to analyze the institutional reality of education, the profile of its students.
\end{abstract}

Keywords: Participation. Family. Education.

\footnotetext{
${ }^{1}$ Faculdade de Ciências Humanas do Sertão Central (FACHUSC). E-mail: sheyllambf@ hotmail.com;

${ }^{2}$ Faculdade de Ciências Humanas do Sertão Central (FACHUSC).

${ }^{3}$ Mestrado em Educação em Ciências pela Fundação de Apoio à Universidade Federal do Rio Grande do Sul, Brasil. Professora da Faculdade de Ciências Humanas do Sertão Central (FACHUSC). E-mail: socorrosobral@bol.com.br
} 


\section{Introdução}

A relação escola e família precisa ser analisada do ponto de vista pedagógico e cultural, tanto no que se refere aos valores, quanto ao ensino-aprendizagem. $\mathrm{O}$ objetivo desse estudo foi portanto, analisar as interações família família/escola. Falar em parceria é fácil, construí-la é um trabalho exigente que as Instituições de Ensino terão de levar em consideração as condições reais da família e, também, desses novos filhos/alunos. São instituições diferentes, ambas em crise, sendo criticados pelo que "não" fazem e deveriam fazer numa realidade de intensas transformações. Por mais que seja criticada a escola, e a família vista como desestruturada, para enfrentar as atuais dificuldades, precisam dessa parceria. A escola que tem a família participando ativamente das suas funções e fazendo acompanhamento da vida escolar dos alunos, poderá conseguir alcançar seus objetivos sem muitas dificuldades.

A missão de educar compete à família, a escola caberá repassar conhecimentos variados a fim de formar cidadãos críticos participativos, competentes, podendo fornecer subsídios para ajudar na formação de uma sociedade mais justa. A escola poderá intervir na educação dos alunos caso algo esteja ocorrendo que venha prejudicar o relacionamento entre os indivíduos que estão se relacionando entre si. Este contato não deve deixar de existir, pois quando a família deixa a escola sozinha, responsável pela aprendizagem dos alunos, vários problemas vão surgindo, acontecem acomodações e ambos passam a se culparem, devido às dificuldades que passam a enfrentar essa foi a justificativa do estudo. Por esta razão a surge a hipótese de que a escola deve repensar e buscar manter essa relação escola/família no sentido de construir uma nova linha de trabalho em prol de uma aprendizagem de qualidade, democrática que vise à autonomia e a cidadania de toda comunidade escolar e daí vem o questionamento como está a relação família/escola?.

Este trabalho foi desenvolvido utilizando os seguintes instrumentos metodológicos: pesquisas bibliográficas através de leituras, para diagnosticar as principais dificuldades enfrentadas na atual realidade em que vivem as escolas e as famílias, devido à falta de integração entre ambas.

A pesquisa qualitativa propicia vários métodos relacionados ao tema escolhido, possibilitando assim um embasamento teórico para fundamentação de um estudo mais aprofundado sobre as dificuldades enfrentadas pela escola, devido a ausência da família, sendo 
considerada fonte, todo material imprescindível a elaboração do trabalho de pesquisa através de entrevistas com pais, professores e coordenadores para situar a situação vivida. A partir destes conceitos, alguns procedimentos contribuições para ajudar a escola a melhorar a relação com a família, orientando para que a parceria escola/família tenha resultados positivos em relação à aprendizagem, comportamento, relacionamento e interação dos alunos para com a escola. Nem sempre as críticas destinadas a escola, pelo fracasso na aprendizagem dos alunos são fundamentadas. Baseada nessa realidade foi possível diagnosticar que a parceria da escola com a família, tem papel importante no processo significativo do ensino-aprendizagem.

\section{Tudo Começa na Família e na Escola}

Como falar de Inclusão numa sociedade tão exclusiva? Como de repente deixar para trás, estigmas, preconceitos, estereótipos, tabus, barreiras, que se perpetuam na História Humana desde a origem do Homem? Como esquecer subitamente tudo o que a pessoa com deficiência vem sofrendo no decorrer de suas vidas? E por que não dizer que a era contemporânea resolveu adotar nos seus sistemas educacionais, uma educação inclusiva, uma escola onde caibam todos os mundos, abrindo as portas para todos?

É muito fácil traçar modelos, criar novas terminologias, novas diretrizes e metas quando se está bem distante da realidade de um sistema educacional que vive no naufrágio, onde todos desejam nos seus discursos políticos uma educação de qualidade para todos, mas que na prática não acontece. Já se fazem alguns anos que grandes encontros, congressos, seminários e conferências a nível mundial mostraram em seus documentos a necessidade de incluir pessoas com deficiências no convívio entre os ditos alunos normais. Isso, portanto não é nenhuma novidade, nenhum algo extraordinário, que venha causar tanta referência, tanto embaraço por parte ainda de alguns professores dentro do contexto educacional.

A Inclusão acontece dentro de cada pessoa. No momento em que nasce um ser com deficiência e este ser é acatado, aceito, amado lá no momento da concepção, da gestação, do nascimento, do pós-nascimento, já no seio familiar inicia o processo inclusivo. Promover a inclusão significa, sobretudo uma mudança de postura e de olhar acerca da deficiência. Implica em quebra de paradigmas em reformulação do nosso sistema de ensino para a conquista de uma 
educação de qualidade, na qual o acesso, o atendimento adequado e a permanência sejam garantidos a todos os alunos, independentemente de suas diferenças e necessidades.

\footnotetext{
“Os caminhos pedagógicos da inclusão se fundamentam, portanto, na diferença dos seres humanos, na singularidade de cada um de nós e nas possibilidades que o caráter multiplicativo e transformador da diferença nos confere" (MANTOAN, 2013).
}

\section{A Família nos dias Atuais}

Mesmo diante da realidade, onde é preciso equilibrar a sustentação econômica e o convívio familiar, corrompidos pelos avanços dos quais a sociedade vem passando, mudanças essas que afetaram as famílias transformando na maioria das vezes totalmente suas rotinas e levando as pessoas a terem uma vida fora do chamado padrão familiar. A escola precisa que a família acompanhe o desenvolvimento no ensino-aprendizagem dos seus filhos. Incentivando, cobrando deles a execução das tarefas escolares.

Para se ter uma boa relação entre família e escola é preciso se basear principalmente em respeito, tanto que a organização das Nações Unidas, trouxe o tema para reflexão ao instituir o Ano Internacional da Família. Acreditando nas capacidades de seus membros de manter e educar seus dependentes para a vida, afirma Antônio Carlos Gomes da Costa, presidente da Organização Não-Governamental Nodus Faciendi: Acredita que em cada casa deveria existir um educador familiar: a pessoa que "adota" a criança em termos de orientação.

\footnotetext{
"Podem ser o pai ou a mãe, mas isso não é regra. Tem de ser alguém interessado no processo de aprendizagem, não importando o preparo intelectual nem o vínculo biológico, sim o afeto. "(COSTA, in: REVISTA NOVA ESCOLA, 2006, p.35).
}

A família é o primeiro grupo com o qual a criança convive e seus membros são exemplos para a vida. No que diz respeito à Educação é preciso que a escola faça um trabalho de conquista. O bom relacionamento deve começar na matrícula e se estender a todos os momentos, a realidade da família hoje é dura, mas nesse caso em que a família não ajuda a desenvolver e dar continuidade ao processo de ensino-aprendizagem, o melhor a se fazer, segundo a coordenadora pedagógica em seu relato que diz: "se a família não ajuda a dá continuidade às atividades desenvolvidas pela escola, o melhor a se fazer: enfatizar mais ainda na escola, o que o aluno aprende ali, ele irá levar para casa’'( MENDONÇA, 2009). 
Diante da realidade a qual as escolas enfrentam devido á ausência da família, e que vem gerando grande dificuldade é que a escola não deve desistir de buscar essa parceria, sem culpas, é impossível haver aproximação quando só são marcados encontros para falar de problemas. Isso causa antipatia e repulsa. A escola deve buscar na família uma aliada, integrando-a no seu contexto, a fim de fortalecer e buscar melhoria para o ensino público brasileiro, para isso é preciso ter diálogo, parceria, cumplicidade, participação da família. Envolver os familiares na elaboração da proposta pública pedagógica, do Regimento Interno, enfim em todo contexto escolar, pode ser uma das metas para que a escola possa manter esse relacionamento mutuo com a família: Segundo o professor Silva (2007), afirma que: “'A escola hoje, já não é referência para algumas famílias. Elas falam mal da escola na presença das crianças, como uma criança que ouve a família criticar sua escola vai ter respeito e obediência'.

Assim a família deve-se ter cuidado com comentários degradantes a respeito da escola. A família e a escola são dois âmbitos educacionais tensos, tanto no seu interior quanto na sua relação um com outro. Outras instâncias consideradas sócio educativo que tiveram também um papel muito forte foram: O Estado e a Igreja, nos tempos atuais essas instâncias vem perdendo o poder e o espaço que tiveram em tempos passados no sentido da formação indivíduo. Uma das tensões a que referimos acima advém do fato que a escola e a família, além de terem seus respectivos papeis enfraquecidos parecem cada vez mais distantes e contrários no processo educativo das crianças e jovens. Não é difícil constatar no cotidiano esta distância e contrariedade, sobretudo, quando os pais, ao invés de participarem ativamente do processo educativo dos seus filhos e apararem as diretrizes que são propostos e estabelecidos na escola fazem claramente o inverso. A escola também não poderá ir contra às normas estabelecidas pela família, para não haver um confronto entre família e escola. "Os pais não estão conseguindo educar seus filhos. Filhos crescem com cuidados materiais, escolas, mas sem equivalentes cuidados para a formação de valores pessoais, profissionais e sociais'’(TIBA, 2011).

O afastamento e a falta de diálogo da família com a escola se deve a necessidade, cada vez maior dos pais trabalharem fora para poder manter sua família, trabalho esse com jornadas que na maioria das vezes causam desencontro entre pais e filhos. Para suprir essa carência deixada pelos pais, a maioria das crianças e jovens estão trocando, interesse e outras formas sedutoras que com o pretexto de entreter, informar e formar opinião ganhou cada vez mais espaço e importância na vida das pessoas. Eles acabam funcionando, em muitas casas como 
substituto da formação vinda da educação familiar e escolar. Para reforçar essa concepção Rosa Maria Marcelo afirma:

\footnotetext{
"Em diversos ambientes familiares a televisão funciona como babá das crianças ou como passa tempo. Com isso, temos a todo o momento a veiculação, ora mais ora menos explicita, de orientações, valores, ideias, práticas e posturas que pouco contribuem para o desenvolvimento saudável e integral da personalidade de nossas crianças e jovens" (MARCELO, 2009, p. 198).
}

Essa realidade enfrentada pela família tem gerado cada vez mais o individualismo das pessoas, no ambiente familiar e consequentemente também tem repercutido na relação família e escola. É justamente aqui que entra em cena uma das questões dos limites. Dada a ausência da família e as limitações da escola, quem dá a medida para a ação à criança e ao jovem? Como a família e a escola podem estabelecer a disciplina como algo fundamental na formação do indivíduo? Diante da realidade vivida pela família e pela escola onde ambas convivem com esses novos modelos de educação. A postura da escola deve ser de nunca desistir de trazer a família cada vez mais para dentro da escola, integrá-la no seu contrato, pois ainda poderá ser grande aliada para alcançar suas metas, para isso segundo a Psicóloga e Professora Rosely Sayão afirma que: "A relação entre escola e família deve ser recuperada, no sentido de construir uma nova parceria em prol de uma educação democrática, que tenha em vista a autonomia e a cidadania" (SAYÃO, 2007, p. 41).

\section{Escola e Família: Parceiras na Aprendizagem}

Para formar cidadãos críticos participativos, capazes de atuar na sociedade, com capacidade de contribuir para a formação da mesma, se faz necessário que a escola complemente, dê continuidade a educação alicerçada pela família do aluno, mas para que esse trabalho seja realizado pela escola é preciso que a família passe a se integrar, faça parte seja parceira da escola, para que juntas tracem metas que possam ser desenvolvidas pela escola, e que através dessas metas desenvolvidas, venham as duas instituições, escola e família alcançar objetivos almejados, resultados satisfatórios, no ensino-aprendizagem.

A lei de Diretrizes e bases da Educação Nacional deixa claro em seu Art. $2^{\circ}$ quando afirma que: "Educação é dever da família e do Estado, inspirada nos princípios de liberdade e 
nas ideias de solidariedade humana, tem por finalidade o pleno desenvolvimento do educando, seu preparo para o exercício da cidadania e sua qualificação para o trabalho" (BRASIL, 1996 p.09).

A sociedade passou por várias modificações as quais essas mudanças interferem na vida familiar, hoje, por exemplo, as mães trabalham fora, e a escola precisa planejar, até que ponto ela pode interferir na educação dos seus alunos, que trabalho pode ser realizado que venha suprir efeitos positivos para a criança que a família, passa para escola toda responsabilidade de educar. Por conta de todo esse processo de modificação pela qual ou sociedade vem passando, a família perdeu alguns valores, como por exemplo, o diálogo com os filhos, que diminui muito. A família hoje já não faz as refeições juntas, que no passado era um momento sagrado, de grande valor moral, não têm mais tempo ou talvez hábito de se encontrarem, perdeu esse referencial familiar, que com certeza trouxe prejuízo para a educação das novas e futuras gerações.

A escola então começou a sentir esse distanciamento, ficando sozinha, precisando preencher lacunas referentes à educação dos alunos, que seriam tarefas da família. A dificuldade de aprendizagem que a escola hoje enfrenta, atribui-se boa parte a essa ausência da família na escola, essa falta de acompanhamento por parte da família, que deixa o aluno desmotivado em relação à escola, lógico que tudo isso vem influenciar negativamente na aprendizagem do aluno. Naturalmente, depois da família é na escola que as crianças permanecem mais tempo, mas não compete a escola a função de educar sozinha, a escola pode ajudar, dá sua contribuição quando acontece a parceria. Quando a escola trabalha em parceria com a família ela passa a entender melhor o contexto ao qual o aluno está inserido, daí poderá intervir com mais clareza, melhorando o processo de ensino-aprendizagem.

A realidade é difícil, mas quando a família é ausente, a escola deve desenvolver ações que possa aproximá-los, e que ela venha fazer parte da escola, e quando isso não acontece, o melhor a fazer no momento, enquanto espera esse processo acontecer é dar continuidade ao seu projeto de integração da família com a escola, é enfatizar mais ainda a formação dada na escola ao aluno, para que ele possa levar para casa esse aprendizado, e que a família comece a refletir e sentir a necessidade de participar junto à escola, da vida escolar dos alunos.

A escola não deve desistir nunca de buscar essa parceria, é preciso muita cautela, o trabalho deve ser feito, sem cobranças, sem apontar culpados, devendo buscar na família reforço, integrando-a no seu contexto, a fim de fortalecer e buscar melhorias para o ensino 
público brasileiro. Para que todo esse processo aconteça é necessário, diálogo, parceria, cumplicidade, clareza, participação da família em todo processo vivido pela escola, principalmente na construção da Proposta Política Pedagógica. Afinal, no Estatuto da Criança e Adolescente, Art. 53, parágrafo único, nos afirma: É direito dos pais ou responsáveis, ter ciência do processo pedagógico, bem como participar da definição das propostas educacionais.

\section{Os Desafios da Parceria: Família - Escola-Comunidade}

Esta abordagem sobre família e escola, mostra como cada uma deve agir diante dos problemas encontradas nas unidades de ensino e como contribuir para juntas resolverem situações que venha atrapalhar o desempenho dos alunos. Quando tudo vai bem, ninguém pensa em discutir a relação escola e família. Basta o boletim a disciplina o comportamento do aluno não atender as expectativas da escola ou da família, começa o jogo de empurra escola coloca a culpa na família, alegando que a família está desestruturada, que não impõe limites nos filhos e nem se interessam pela educação, a família por outro lado, acusa a escola de negligência, quando não tacha o próprio filho de irresponsável. Nessa briga nada saudável, a única vitima é o aluno.

A escola e a família têm que terem os mesmos objetivos, zelar pelo o ensino de qualidade e pelo sucesso na aprendizagem do aluno, ou seja, fazer a criança se desenvolver em todos os aspectos. A escola deve arrumar formas de fazer um trabalho diferenciado, para que possa transformar os pais ou responsáveis pelos alunos em parceiros, e diminuir os índices de evasão, repetência e violência dentro da escola. Existem várias maneiras desse casamento dá certo, manter um bom relacionamento com a família; solicitar a participação dela nas tarefas educacionais desenvolvidas pela escola, envolver as famílias na elaboração da Proposta Política Pedagógica, pode ser ferramentas para a escola encabeçar um bom entrosamento com a família, através de atos como esses, a família pode resgatar a credibilidade pela escola e passa a aprender a importância do trabalho coletivo.

A falta de tempo é um dos fatores principais alegado pelas famílias do não comparecimento delas na escola e do não acompanhamento da vida escolar dos filhos. Contudo, essa realidade não pode servir de desculpa para a falta de contato entre escola e família. Por esta razão a escola deve desenvolver ações que ajudem a suprir essa carência, por exemplo, 
abrir os portões para a família pode ser uma forma significativa para fortalecer essa parceria, só que é uma via de mão dupla, ao mesmo tempo em que requisita a parceria para melhorar o relacionamento, a escola deve se preparar para receber críticas e implantar sugestões. O importante é que a família se engaje totalmente, os mais comprometidos, ainda que seja minoria, têm a capacidade de influenciar o restante da comunidade escolar e mudar a rotina da escola. E essa mudança, pode ser o segredo do sucesso para uma relação duradoura e com um final proveitoso e feliz na aprendizagem dos alunos.

Abrir às portas a participação de familiares e da comunidade ajuda os alunos a ter sucesso na vida escolar e colabora para diminuir a evasão e a violência. (NOBILE 2006, p.32).

A parceria da escola com a família deve ocorrer em vários níveis e momentos. $\mathrm{O}$ interesse da família pela vida escolar do aluno é maior, quando as crianças são pequenas. Contudo, o tempo passa, o aluno cresce e os adultos acham que ela já sabe se cuidar e não precisa mais de ajuda. Mas a realidade é diferente, quanto mais autonomia tem o aluno mais a parceria entre a família e a escola deve se fortalecer. É nessa fase que os alunos vão construir sua própria identidade e seu projeto de vida, tarefa nada fácil nem para a escola nem para a família. Por isso quanto mais esses dois pilares estiverem em sintonia, mais fácil fica para eles planejarem o futuro e executarem esse projeto já no presente. É importante que a escola crie espaços para discutir valores e promova ações sociais comunitárias, voltadas para o mundo globalizado.

Quanto aos pais analfabetos ou alfabetos funcionais, a escola pode fazer um trabalho de mobilização um acompanhamento a essas famílias, mostrando que elas não são responsáveis pelo processo de aquisição do conhecimento do aluno, mas que o interesse delas pode fazer toda a diferença na aprendizagem, fazer a família entender que o aluno evolui com mais facilidade quando percebem que os responsáveis por ele valorizam o seu desenvolvimento na aprendizagem, mesmo sem intimidade com a escrita, os familiares estão aptos a uma série de ações que contribuem para uma aprendizagem com mais desempenho e eficiência.

* Falar sobre a importância de sabre ler e escrever para a vida profissional.

* Escutar o filho lendo em voz alta, com paciência e corrigi-lo caso erre ou gagueje.

* Estimular o interesse por livros revistas ou jornais, pedindo que traga esse material da escola.

* Não fazer da leitura uma obrigação nem castigo.

* Pedir que escrevam bilhetes, listas de compras etc. 
* Mostrar para o filho o quanto a leitura é importante na vida do cidadão e a falta que ela faz na vida daqueles que não a tem. Uma das vantagens de se ter uma relação fortalecida entre escola e família, é que os pais exigem cada vez mais da escola, qualidade no ensino aprendizagem. Portanto a escola deve se organizar e construir o seu plano de trabalho logo no inicio do ano letivo. Convidar os pais para juntos elaborar uma lista de ações para ajudar a estreitar esse contato.

Valorizar a família, orientar no sentido de incentivar as boas relações com a escola e todos que fazem parte deste ambiente. Essa certeza se evidencia no cotidiano escolar onde são visíveis por exemplo, os resultados positivos do trabalho feito pela escola com a família dos alunos com dificuldades de aprendizagem, após a família tornar-se parceira da escola e acompanhar a vida escolar dos alunos, foi possível observar uma melhora notável dessas dificuldades.

Portanto, mais uma vez enfatizo que é necessário e de suma importância no processo ensino-aprendizagem que a escola mantenha uma relação de parceria com a família, e para que juntas possam conseguir bons resultados e acabar ou pelo menos sanar em partes a imagem negativa de que a família não esta interessada e nem valoriza a escola.

\section{Metodologia}

A metodologia escolhida para desenvolver este trabalho aconteceu através da pesquisa bibliográfica, permitindo reflexões críticas e possibilitando alteração da realidade social, com base na corrente teórica do materialismo dialético. Ao realizar o projeto fez-se necessária uma análise da realidade institucional da educação, do perfil de seus alunos.

\section{Considerações Finais}

Finalmente, na relação família/escola, foi possível perceber um sujeito sempre espera algo do outro. E para evitar que isto de fato ocorra é preciso que ser capaz de construir de modo coletivo uma relação de diálogo mútuo, onde cada parte envolvida tenha o seu momento de fala, onde exista uma efetiva troca de saberes. Notou-se que a construção dessa relação implica 
em uma capacidade de comunicação que exige a compreensão da mensagem que o outro quer transmitir, e para tanto, se faz necessário, a competência e o desejo de escutar o que está sendo expresso, bem como a flexibilidade para apreender ideias e valores que podem ser diferentes dos nossos.

Por parte da escola recomenda-se: respeito pelos conhecimentos e valores que as famílias possuem, evitando qualquer tipo de preconceito e favorecendo a participação dos componentes da instituição familiar em diferentes oportunidades, estimulando o diálogo com os pais e possibilitando-lhes, também obter um ganho enquanto sujeito interessado em evoluir e se aperfeiçoar como seres humanos e cidadãos compromissados com a escola e com a transformação da realidade.

Por parte da família recomenda-se: valorizar a escola, mostrar para o filho/aluno, que a escola é o único caminho que pode levá-lo a uma aprendizagem de sucesso, para a vida profissional, e na vida real. Que só através da educação é que ele vai poder participar se integrar na sua comunidade, podendo interagir, dando sua contribuição para a construção de uma sociedade mais justa. Procura-se mostrar neste trabalho de pesquisa bibliográfica, como está ocorrendo à relação da família com a escola nos dias atuais enfatizando as principais consequências dessa participação.

Ao analisar os dados coletados pode-se afirmar, que apesar da participação da família não ocorrer de uma forma global, essa relação tem grande influência na aprendizagem dos alunos. A família tem o poder de despertar nas crianças o desejo de querer aprender e permanecer na escola. Os pais podem ajudar a escola de várias formas, que vai desde o momento da matrícula ate a conclusão do ano letivo, mostrando ao filho a importância de que ele precisa permanecer na escola. Da mesma forma que a família tem o poder de incentivar, ela pode desestimular quando ela não dá valor, nem acredita na escola/educação.

Esta pesquisa comprovou também que na atualidade a relação da família com a escola anda muito conturbada, e que ambas, vivem transferindo suas responsabilidades, chegando a se tornarem em vez de parceiros, rivais. Na atualidade escola e família não vêm conseguindo se entender, suas metas são as mesmas, porém na hora de colocá-las em prática, começa, o jogo de empurra-empurra. São vários os fatores que causam este distanciamento, no entanto, tanto a família quanto a escola sabem o potencial que cada uma tem em relação ao aluno, e que quando passam a trabalhar juntas os resultados são positivos para ambas . 


\section{Referências}

BRASIL. Estatuto da Criança e do Adolescente - Lei no 8069, de julho de 1990. L.IV p. 18, ART. 60.

BRASIL. Lei de Diretrizes e Base da Educação (LDB), Lei no 9394 de 1996 T. 1 Art. 1º, p. 7, T. III, Art. 5.

CORTELLA, Mário Sérgio - Educação Convivência e Ética. Cortez Editora. São Paulo, 2015.

COSTA, Antônio Carlos Gomes - Escola/família.Revista Nova Escola - Ministério da Educação - FNDE, Brasília, junho/julho - 2006.

MANTOAN, Maria Teresa. Disponível em: <https://inclusaoja.com.br/category/ opiniao/maria-teresa-mantoan/ > Acesso em 10 out. 2016.

MARCELO, Rosa Maria - Relação família - Escola - São Paulo, FTD, 2009.

MENDONÇA. I. Interações. Revista Educar para crescer. Editora Abril. Disponível em: <http://educarparacrescer.abril.com.br/>. Acesso em: 30 out. 2016.

NOBILE, E. F. Escola e família constuindo novas relações, Revista Nova Escola- Junho / Julho, 2006, p. 32.

SAYÃO, Rosely. Ser e fazer. Folha de S. Paulo, São Paulo, 29 jul. 2014. Disponível em: <http://www1.folha.uol.com.br/colunas/roselysayao/2014/07/1492646-ser-e-fazer.shtml>.

Acesso em: 30 set. 2016.

SILVA, Claudete Maria - Prof ${ }^{a}$. Formação, Magistério, Fevereiro, 2007.

TIBA, Içami. Pais e Educadores de Alta Performance. Integrare Editora e Livraria Ltda., 2011.

\section{Como citar este artigo (Formato ABNT):}

FERREIRA, Sheylla Michelle Barros; SOBRAL, Maria do Socorro Cecílio. A Importância da Participação da Família na Educação Escolar. Id on Line Rev.Mult. Psic., 2018, vol.12, n.42, Supl. 1, p. 491-502. ISSN: 1981-1179.

Recebido: 08/11/2018;

Aceito: 12/11/2018 